\title{
Nota sobre as origens da filosofia da história
}

\author{
Notes regarding the beginnings of the philosophy of history
}

\author{
Pedro Paulo Pimenta \\ pedronamba@gmail.com \\ (Universidade de São Paulo, São Paulo, Brasil)
}

\begin{abstract}
Resumo: Trata-se de encontrar, na interpretação que Kant e Herder respectivamente propõem da história filosófica de David Hume, uma das fontes daquela disciplina do pensamento filosófico que, a partir da denominação de Herder, ficou conhecida como filosofia da história.
\end{abstract}

Palavras-Chave: filosofia; história; experiência; antropologia; transcendental.
Abstract: The aim of the text is to show how the constitution of a philosophy of history as a discipline of philosophical thought depends in a certain measure of the way in which Kant and Herder interpret the philosophical history of Hume.

Keywords: philosophy; history; experience; anthropology;transcendental.

Parece não haver dúvida de que os alemães inventaram a disciplina que a partir de Hegel ficou conhecida como "filosofia da história"1 ${ }^{\prime \prime}$ A data dessa invenção é controversa, mas proporemos, como referência geral, os dez anos que separam a publicação do escrito de Herder, Também uma filosofia da bistória (1774) do surgimento do opúsculo de Kant, Ideia de uma bistória universal de um ponto de vista cosmopolita (1783).

Mais discutível é que antes dos alemães toda história tenha sido meramente factual. Lembremos a frase de Gibbon, extraída de um escrito de 1761: "Se nem todos os filósofos são historiadores, seria ao

1. Ver a esse respeito o volume organizado por Ricardo Ribeiro Terra: KANT, I. Ideia de uma bistória universal de um ponto de vista cosmopolita. $2^{a}$ edição. São Paulo: Martins Fontes, 2004, onde, além de texto do próprio Terra, encontram-se também exposições de Gérard Lebrun e José Arthur Giannotti. 
menos desejável que todos os historiadores fossem filósofos ${ }^{\prime \prime 2}$. Segundo Gibbon, somente dois nomes correspondem ao caráter do historiador filosófico: Tácito na Antigüidade, Montesquieu na época moderna. E, de fato, se percorrermos não só Declínio e queda do império romano (1775), como outros clássicos da historiografia ilustrada - a História da Inglaterra de Hume (1754), o Ensaio sobre os costumes de Voltaire (1759), Ensaio de bistória da sociedade civil de Ferguson (1767), a História da América de Robertson (1777) - veremos que esses autores tomam Tácito e Montesquieu como modelos, adotados criticamente, tanto em questão de método quanto em questão de conteúdo e análise factual (lembrando que coube a Montesquieu a promoção de Tácito a esse patamar; Voltaire ainda insiste em preferir Tito Lívio) $)^{3}$.

Haveria muito a dizer sobre esse gênero de investigação filosófica, cujo impacto foi e continua sendo enorme, em diversas áreas das ciências humanas, mas que os filósofos, salvo honrosas exceções, preferiram ignorar. A intenção desta breve exposição é mostrar como, nos mencionados escritos de Herder e de Kant, a nascente filosofia da história procurou legitimar as suas aspirações, certamente originais, frente a um saber estabelecido que ameaçava, de antemão, desautorizá-las. Nesse embate, o nome de Hume teve um lugar especial, por se tratar, sem dúvida, daquele que primeiro pôs em prática o programa de uma análise filosófica da experiência política moderna. Medindo forças com o gênio de Hume, Kant e Herder visam, cada um a seu modo, encontrar um lugar para o saber que desponta. Não proporemos aqui uma análise conceitual desse embate, apenas esboçaremos um quadro geral, para, quem sabe, uma investigação ulterior, mais aprofundada.

\section{$* * *$}

Em 1783, no opúsculo "Ideia de uma história universal de um ponto de vista cosmopolita", Kant adverte que "é um projeto estranho e aparentemente absurdo querer redigir uma história segundo uma ideia de como deveria ser o curso do mundo, se ele fosse adequado a

2. GIBBON, E. Essai sur l'étude de la littérature, 1762, § 52. Edição eletrônica Eighteenth Century Collections online.

3. Cf. MOMIGLIANO, A. Tacitus and the tacitist tradition. In: The classical foundations of modern bistoriograpby. Berkeley: University of California Press, 1990, p. 111. 
certos fins racionais - um tal propósito parece somente poder resultar num romance ${ }^{\prime \prime}$. Essa ideia, no entanto, "poderia se tornar útil" caso se aceitasse "que a natureza não procede sem um plano nem um propósito final; e mesmo se somos míopes demais para penetrar o mecanismo secreto de sua disposição, ela poderá nos servir como fio condutor para expor, ao menos em linhas gerais, como um sistema, o que de outro modo seria um agregado, sem plano, das ações humanas". A passagem do agregado ao sistema, porém, só é possível caso se leve em consideração a experiência mesma, a massa dos fatos que constituem a história do passado dos homens, remoto ou recente, com vistas a uma unificação mediante conceitos.

Essa reconstituição enviesada da experiência deve tomar certas precauções, para evitar a mistura dos fatos com a ficção. Como explica Kant em "Começo conjectural da história humana" (1786), uma coisa é "formular aqui e ali conjecturas, com o objetivo de completar as lacunas de nossos documentos", na medida em que esses raciocínios hipotéticos, feitos por analogia com fatos conhecidos, em nada interferem na ideia de um curso regular da experiência. "Contudo", prossegue ele, "apoiar uma história apenas em conjecturas é, ao que parece, fazer tão só o esboço de um romance. Aliás, uma tal obra não mereceria sequer o título de história conjectural, mas simplesmente o de mera ficção". Banida "do curso das nações humanas", a conjectura é reabilitada num outro exercício, complementar, de reconstituição "dos primórdios dessa história, porque se trata de uma obra da natureza"5.

Uma história segundo a ideia de um "curso necessário do mundo" postula uma intencionalidade da natureza atuando no homem; uma conjectura acerca dos primórdios da história humana localiza, a título provisório, ou mesmo de ideia reguladora, para uso da razão, o ponto de inflexão em que o homem, no interior da natureza, é impelido, por um propósito indeterminado, a realizar a destinação (racional ou moral) de sua espécie, ou seja, a sua destinação natural de ser dotado de razão. O programa de uma filosofia da história se estabelece assim em detrimento do que poderia ser considerado, e realmente era con-

4. KANT, I. Ideia de uma bistória universal de um ponto de vista cosmopolita. Tradução Ricardo Terra e Rodrigo Naves. São Paulo: Brasiliense, 1986.

5. KANT, I. Começo conjectural da bistória bumana. Tradução de Edmilson Menezes. São Paulo: UNESP, 2009, VIII, 109. 
siderado, desde a Antiguidade, como o fundo filosófico ou moral de toda história dos eventos políticos. É que esta, ao centrar a atenção numa polis ou num Estado - a Atenas de Heródoto ou de Tucídides, a Roma de Políbio ou de Tácito - adota um enfoque necessariamente restritivo, que desconsidera a possibilidade de que o gênero humano atue segundo molas que não necessariamente se resumem àquelas que predominaram nessas organizações políticas. O bem da aristocracia romana ou da plebe ateniense não passa de um objetivo circunstancial, e seria absurdo pensar que essas noções de certo e errado esgotariam o poder de representação da razão ou responderiam pelo bem da espécie como um todo. Se a história factual é necessariamente míope ${ }_{i}$ a história universal há de ser clarividente.

Kant sabia, porém, que sem o apoio da história tradicional, a filosofia da história estaria destinada à quimera. Em nota à passagem da Ideia que acabamos de citar, ele diz: "a primeira página de Tucídides (diz Hume) é o único começo de toda verdadeira história". A frase completa de Hume é esta: "a primeira página de Tucídides, em minha opinião, é o começo da verdadeira história. Todas as narrações precedentes são tão misturadas a fábulas, que os filósofos devem deixá-las, em grande medida, para que embelezem os poetas e oradores". Em nota a essa passagem, Hume acrescenta que os historiadores antigos "são mais cândidos e mais sinceros do que os modernos", enquanto estes os superam em acuidade, graças à difusão dos livros, que, com a invenção da imprensa, tornaram-se mais acessíveis, logo mais fáceis de consultar ${ }^{6}$. Nos documentos e nos livros, o historiador encontra suas fontes mais seguras e mais fidedignas, testemunhos lavrados de preferência a partir de experiência direta, compostos segundo regras da gramática de uma língua, e que são assim legíveis e decifráveis, por quem quer que se disponha a lê-los e interpretá-los. A dependência da facticidade histórica em relação ao testemunho direto, lavrado em documento razoado, ou seja, glosado ou comentado por um autor confiável, é tamanha, que Hume não hesita em classificar a história como o conhecimento dos signos da linguagem em que os eventos são transmitidos à posteridade 7 . A contraparte inevitável dessa limita-

6. HUME, D. Of the populousness of ancient nations. In: Essays, moral, political, and literary. Ed. E. F. Miller. Indianapolis: Liberty Fund, 1985, p. 422.

7. Ver HUME, D. A treatise of buman nature. Ed. Selby-Bigge/Nidditch. Oxford: Clarendon Press, 1978, I, 03, 04, p. 83. 
ção do campo de apreensão da verdade histórica é a recusa de valor real a tudo o que dependa de reconstituição indireta de fatos longínquos, de interpretação incerta, de conjectura-lendas, mitos e fábulas, mas também monumentos, templos, peças de utensílio etc. Tais vestígios dão acesso parcial a um passado que de tão nebuloso e confuso só pode ser considerado incerto, e, portanto, desinteressante ${ }^{8}$. Essas composições têm mérito poético, isto é, têm coerência interna e servem ao cultivo da imaginação $(\operatorname{logo}$, podem ser aproveitadas pelos poetas e pelos oradores), mas não devem ser tomadas por um registro fidedigno da experiência. Este instrui a imaginação, na medida mesma em que se apresenta como um produto do seu uso regrado, isto é, do uso refletido dos princípios de conexão entre as ideias, que são o único critério de coerência das ideias, por referência às impressões obtidas junto à experiência9 .

Ora, como no gênero de fonte delimitado por Hume encaixam-se apenas e tão somente, na Antiguidade, os historiadores gregos e os latinos, que fornecem, por sua vez, os cânones da historiografia moderna, a frase de seu ensaio citada por Kant tem um sentido preciso: o começo da história é o começo da história da Europa, tal como registrada pelos gregos, e a história de outras nações - como advertirá Gibbon, um especialista no gênero - só tem interesse na medida em que diga respeito à história da Europa ${ }^{10}$. Não por outra razão Kant afirma que "somente um público instruído que persistiu de seu começo até nós ininterruptamente pode garantir a autenticidade da história antiga". A única diferença em relação a Hume, quanto a esse ponto, é o uso do advérbio ininterruptamente. Hume é mais reticente. Considera que a permanência das fontes documentais não dispensa o trabalho da reinterpretação e do ajuste de perspectiva; sem mencionar que nem tudo o que restou de tempos antigos é testemunho fiel da experiência

8. HUME, D. The bistory of England, from the invasion of Julius Caesar to the 1688 revolution. Ed. William B. Todd, 6 vols. Indianapolis: Liberty Fund, 1983, livro I, cap. 01, abertura (1761).

9. HUME, D. Of the connexion of ideas. In: Pbilosopbical essays concerning buman understanding. $2^{a}$ edição, 1751. Ed. fac-símile. Hildesheim/New York: Olms Verlag, 1978.

10. GIBBON, E. Declínio e queda do império romano. Tradução de José Paulo Paes. São Paulo: Companhia das Letras, 1997, cap. 26, início. Ver também: GIBBON, E. Essai sur l'étude de la littérature. In: Ensaios sobre bistória. Tradução de Pedro Paulo Pimenta. São Paulo: Iluminuras, 2014, § 47. 
(o antigo e o novo testamento são os exemplos mais flagrantes disso). Em todo caso, a ideia de que a leitura está por trás desse gênero da arte de escrever é preservada pelo filósofo alemão, mesmo às voltas com o projeto de uma "história do mundo que de certo modo tenha um fio condutor a priori". É que uma história como essa, caso fosse exequível - Hegel, Marx, os liberais de nosso tempo não hesitariam em concordar que ela não somente é possível como também necessária - não deixaria de ser um desdobramento da história tradicional, supondo-se que esta seja composta, lida e discutida por um século esclarecido. Ouçamos Kant em sua conclusão:

O louvável cuidado com os detalhes com que se escreve a história de seu tempo deve levar cada um naturalmente à seguinte inquietação: como nossos descendentes longínquos irão arcar com o fardo da história que nós lhes deixaremos depois de alguns séculos? Sem dúvida eles avaliarão a história dos tempos mais antigos, da qual os documentos poderiam estar perdidos há muito, somente do ponto de vista daquilo que lhes interessa, ou seja, o que povos e governos fizeram de positivo e de prejudicial de um ponto de vista cosmopolita. Prestar atenção nisto, bem como na ambição dos chefes de Estado e também na de seus servidores, para indicar-lhes o único meio em que sua lembrança gloriosa pode ser levada à mais distante posteridade, pode fornecer além disso um pequeno motivo adicional para um ensaio de história filosófica ${ }^{11}$.

Toda essa maneira de falar - "fio condutor", "história do gênero humano", "propósito da natureza" - embora seja muito estranha a Hume, não está assim tão distante de uma leitura favorável da empreitada humiana. Numa lição proferida por volta de 1775, Kant inscrevera a História da Inglaterra no quadro de uma antropologia, estudo da "natureza da humanidade" que não se confunde com o "comportamento fortuito dos seres humanos ou com o estado das coisas" em dadas circunstâncias. O interesse da antropologia é pelo que tem "relação com a conduta prudente dos seres humanos", e seu propósito é "trazer fenômenos sob regras". A importância da história para esse ramo da filosofia é clara. "Ninguém até aqui", declara Kant,

11. KANT, I. Ideia de uma bistória universal de um ponto de vista cosmopolita, proposição 09. 
Escreveu uma história do mundo, que fosse, ao mesmo tempo, uma história da humanidade, apenas do estado de coisas e das mudanças dos reinos, parte que, tomada em si mesma, é enorme, mas que, considerada no todo, é uma trivialidade. Todas as histórias de guerras são a mesma, pois não contêm senão histórias de batalhas. Mas pouco importa, no todo, se uma batalha foi ou não ganha. Mais atenção deveria ser dada à humanidade, em sua História da Inglaterra, Hume provou que isso é possível ${ }^{12}$.

Encontramos nessa passagem o eco destas palavras de Gibbon: "escolher os fatos que devem ser os princípios de nossos raciocínios: percebe-se que a tarefa não é fácil. A negligência ou o mau gosto de um historiador podem pôr a perder, para sempre, um traço único, para atordoar-nos com o ruído de uma batalha"13. É como se Hume estivesse para os demais historiadores na mesma proporção em que Tácito estava para Tito Lívio, este que nos atordoa, aquele que nos ilustra. $\mathrm{O}$ elogio velado sugere que, para Kant, os historiadores filosóficos haviam descoberto que a verdadeira história, por definição, é parte da filosofia. Hume alcançou a humanidade a partir dos ingleses, ao ver que a história da Inglaterra é sobretudo uma história, atribulada e tortuosa, da constituição e da liberdade civil ${ }^{14}$; resta percorrer o caminho contrário, partir da humanidade para chegar aos ingleses, aos franceses, aos alemães etc. como tantas determinações particulares de um mesmo conceito, ou de uma mesma ideia da razão.

Com essa proposta - que certamente escapa ao horizonte de Hume, ou melhor, que Hume recusa deliberadamente - Kant visa contornar a restrição colocada pelo filósofo escocês às inferências a partir da experiência histórica: o tempo pelo qual a história do gênero humano se distende num período breve demais para que se possa chegar a qualquer conclusão taxativa acerca de uma suposta tendência

12. KANT, I. Antropologia Friedländer, 25: 472. In: Lectures on anthropology. Org. A. Wood e R. Louden. Cambridge: University Press, 2012, p. 49 (Tradução desse curso: G. F. Munzel).

13. GIBBON, E. Essai sur l'étude de la litterature, 1762, § 52.

14. HUME, D. The bistory of England, livro II, fim. A liberty a que Hume se refere é um privilégio a que aspiram ou de que desfrutam os membros do parlamento em relação às prerrogativas da Coroa. Sobre esse sentido da palavra, ver HOLANDA, S. B. Uma doença infantil da historiografia. In: Escritos coligidos, vol. 2. Org. Marcos Costa. São Paulo: Unesp/Fundação Perseu Abramo, 2011. 
da experiência humana ${ }^{15}$. Para superar essa restrição, advinda de uma perspectiva limitada, Kant propõe que se interprete a história de um ponto de vista cosmopolita: "mediante a arte e a ciência, nós somos cultivados em alto grau. Nós somos civilizados até a saturação, por toda espécie de boas maneiras e de decoro social. Mas ainda falta muito para nos considerarmos moralizados ${ }^{\prime \prime 16}$. Com essa verdadeira paráfrase do Discurso de Rousseau sobre a desigualdade entre os homens, Kant introduz a filosofia na história - o que é bem diferente de fazer a história filosoficamente. O fim moral da razão independe da história para existir ${ }_{i}$ e esta, se tem um sentido, ainda que provisório, como quer Hume, deve-o à faculdade de fins no homem, que interpreta os eventos como favoráveis ou não à realização da moralidade no mundo.

Não foi Kant, porém o primeiro filósofo alemão a atinar com o relativo mérito filosófico da História de Hume. Entre 1766 e 1768, Herder compôs fragmentos de um plano mais geral de história da literatura em que Hume desponta como o grande historiador surgido na época das Luzes, e como o primeiro a fazer jus, na modernidade, ao espírito filosófico que anima os grandes historiadores antigos notadamente Políbio e Tácito.

Os maiores historiadores chegam ao sumo da excelência quando observam as mudanças ocorridas ao longo do tempo, quando ao narrar não perdem de vista que conduzem o leitor não apenas para fazê-lo ver, mas também para fazê-lo aprender. O maior de todos, a esse respeito, em minha opinião, é o historiador da Grã-Bretanha, Hume, um autor que domina a difícil arte de aplicar as técnicas pragmáticas de um Tácito e de um Políbio de acordo com o gosto de nossa época. [...] Hume é certamente um dos maiores espíritos do nosso tempo, eu o leio sempre, com reverência, mas, por assim dizer, não como historiador, e sim como um filósofo da história britânica. Quem não for capaz de admirá-lo como genial estadista, pensador profundo, penetrante narrador, esclarecido juiz, não é

15. HUME, D. Da liberdade civil. In: A arte de escrever ensaio. Org. Pedro Paulo Pimenta. São Paulo: Iluminuras, 2011, início e HUME, D. The bistory of England, livro II, fim.

16. KANT, I. Ideia de uma bistória universal de um ponto de vista cosmopolita, proposição 07. 
digno de ser o seu leitor. Contudo, por mais que eu queira aprender com ele, o que menos quero aprender - é história. O que me interessa é o que Hume pensa da história, como as coisas se afiguram para ele, como o seu juízo flui de sua representação, como ele imagina os eventos e os povos para quem aconteceram, como ele situa esses eventos, mas não necessariamente como aconteceram, como foram ${ }^{17}$.

Esse elogio revela uma compreensão penetrante da maneira como Hume concebe a história, uma ciência, que é também uma arte literária, cuja validade depende de sua vinculação com a imaginação do próprio historiador que a pratica. Para além da concepção retórica tradicional, da história como um simples gênero pautado por regras estritas e destinado a fins restritos de persuasão, Hume se alça a uma compreensão dos fatos, a partir da lógica como as percepções se conectam na imaginação. A história, como os demais ramos do conhecimento, depende inteiramente da experiência. A mesma lógica que produz o conhecimento da natureza propicia, com alguns ajustes importantes ${ }^{18}$, o conhecimento da vida do homem em sociedade, e não é pouco afirmar, como faz Herder, que da imaginação do próprio Hume depende a inteligibilidade dos fatos narrados em sua história. O historiador filosófico desponta aqui como alguém dotado de um gênio singular, que, por isso mesmo, é capaz de emprestar universalidade à uma história que, de outro modo, ou nas mãos de um autor menor, não teria interesse a não ser para os ingleses ou para os europeus implicados nela diretamente.

Essa interpretação é inteiramente condizente com o que afirma Hume numa primeira versão do ensaio "Da associação de ideias" (então intitulado: "Da conexão de ideias"), onde se mostra que na história a inteligibilidade dos fatos depende quase que exclusivamente da arte com que o historiador os dispõe, de como ele situa os efeitos em relação às causas, do ponto que ele toma como partida, da meta que ele estabelece como chegada da narrativa. É por obra desse trabalho expositivo, que cabe à imaginação, que a razão conseguirá, enfim, for-

17. HERDER, J. G. Da diversidade de gosto e maneira de pensar entre os homens (1766) ${ }_{i}$ Fragmento sobre a história $(1767$ - 68). In: Philosopbical writings. Edição e tradução Michael N. Forster. Cambridge: University Press, 2002, pp. 254 $-55 ; 263-65$.

18. HUME, D. A treatise of buman nature, introdução. 
mular leis gerais em que a constância dos fatos transparece por trás do véu das circunstâncias ${ }^{19}$.

Em 1774, porém, Herder muda de opinião acerca dos méritos de Hume. Onde antes despontava o interesse intrínseco à sua concepção particular dos fatos, predomina em Também uma filosofia da bistória a submissão da História da Inglaterra ao esquema geral adotado pelos historiadores da época da Ilustração. Não é que falte senso filosófico a Hume e aos seus (Voltaire, Robertson); apenas, este é completamente equivocado, de quem "modela o conjunto dos séculos segundo a forma tão específica - quase sempre tão pequena e tão fraca - que o seu tempo lhe oferece"; o que são esses "clássicos fantasmas do crepúsculo... à luz da verdade?", pergunta-se Herder ${ }^{20}$. Perfilando Hume junto aos "historiadores políticos" que compuseram "épicos da história da monarquia", Herder descarta outro mérito da História da Inglaterra além de apresentar uma apologia "da atual arte da governança, o verdadeiro sistema, a ciência destinada à formação da humanidade", obra míope que não vê sequer os limites que imediatamente se põem a essas descabidas pretensões ${ }^{21}$.

Essa crítica contundente, virulenta mesmo - que se estende a uma sátira desleal da História da Carlos $V$, de William Robertson -, é realizada a partir de um ponto de vista que transcende a experiência histórica, tal como vista pelos apologistas ilustrados. Pois o que interessa a Herder, o que leva-o a mostrar a historiografia humiana sob uma luz totalmente desfavorável, é a perspectiva da formação (Bildung) da humanidade, solução para o mesmo problema, o do progresso das artes e ciências, com que Kant se debaterá anos depois, e que denomina como moralização. A imaginação de Hume, outrora poderosa e senhora de si, tornou-se para Herder mesquinha, subserviente aos preconceitos do século. Pouco importa que a História da Inglaterra ofereça o contrário mesmo de uma apologia da arte moderna de governar, que aparece ali como tateante e desastrada; pois Herder tem razão ao identificar em Hume um sentimento de satisfação com os progressos

19. HUME, D. Of the connexion of ideas; Of liberty and necessity. in: Pbilosophical essays concerning buman understanding. $2^{a}$ edição, 1751. ed. fac-símile. Hildesheim/ New York: Olms Verlag, 1978.

20. HERDER, J. G. Também uma filosofia da bistória. Tradução de J. M. Justo, Lisboa: Antígona, 1995, 2ª seção, p. 41.

21. HERDER, J. G. Também uma filosofia da bistória, $2^{\mathrm{a}}$ seção, pp.82-83. 
realizados pela liberdade, no estreitíssimo quadro institucional oferecido pela malajambrada constituição inglesa ${ }^{22}$.

O nosso século, lamenta Herder, "é o grande século da dúvida, e do levantar de ondas". Não parece haver mais lugar para o ceticismo honesto de um Montaigne; somente para os que "tudo duvidam ao mesmo tempo, e produzem as mais ousadas opiniões" - "Voltaire, Hume, o próprio Diderot" ${ }^{\prime \prime 2}$. Não é suficiente, para Herder, que Hume, diferentemente de Voltaire ou de Robertson, questione, na História da Inglaterra, a viabilidade conceitual da noção de progresso, que ele substitui pela de refinamento, provisório e precário, das maneiras e costumes dos homens; pois mesmo assim trata-se de uma proposta bem exígua, aos olhos de quem não se contentaria com nada menos que uma investigação filosófica do caráter natural do gênero humano.

A partir dessas considerações, seria possível explorar as diferenças que opõem, na década de 1780, o pensamento histórico de Kant, que se inclina cada vez mais por uma filosofia do direito, e de Herder, cuja inflexão pela antropologia é marcada já em 1774 e chega ao ponto culminante na Ideia de uma filosofia da história da humanidade (1781), que, como se sabe, foi resenhada em termos bastante negativos por Kant ${ }^{24}$. Seja como for, a indisposição de Herder para com Hume, autor que, nos domínios do pensamento histórico, Kant nunca chegou a rejeitar, talvez sirva para justificar a avaliação posterior de LéviStrauss, que, às voltas com as origens da etnologia, encontra na "escola alemã" aquela que, "de Goethe a Fichte, e de Fichte a Herder (sic.), progressivamente se afastou das pretensões generalizantes para deter-se antes nas diferenças do que nas semelhanças e defender, contra a filosofia da história, os direitos e as virtudes da monografia" ${ }^{\prime 25}$. Com essa omissão deliberada do nome de Kant, o grande etnólogo talvez tenha se esquecido de que para este uma filosofia da história só

22. HUME, D. The bistory of England, capítulo 71, volume VI.

23. HERDER, J. G. Também uma filosofia da bistória, $2^{\mathrm{a}}$ seção, p. 45.

24. Ver ZAMMITTO, J. Kant, Herder and the birth of antbropology. Chicago: University of Chicago Press, 2002.

25. LÉVI-STRAUSS, C. L'éthnologie devant la condition humaine. In: Le regard eloignée. Paris: Plon, 1983, p. 50. 
é viável aliada se a uma antropologia, ou ao conhecimento do homem no mundo - tarefa que para Hume, desde sempre avesso às generalizações, constitui o cerne da prática do historiador.

\section{Referências}

GIBBON, E. Essai sur l'étude de la littérature. In: Ensaios sobre bistória. Tradução de Pedro Paulo Pimenta. São Paulo: Iluminuras, 2014.

GIBBON, E. Essai sur l'étude de la littérature. Edição eletrônica. Eighteenth Century Collections online.

GIBBON, E. Declínio e queda do império romano. Tradução de José Paulo Paes. São Paulo: Companhia das Letras, 1997.

HERDER, J. G. Da diversidade de gosto e maneira de pensar entre os homens (1766). In: Pbilosopbical writings. Edição e tradução de Michael N. Forster. Cambridge: University Press, 2002.

HERDER, J. G. Fragmento sobre a história $(1767$ - 68). In: Pbilosopbical writings. Edição e tradução de Michael N. Forster. Cambridge: University Press, 2002.

HERDER, J. G. Também uma filosofia da bistória. Tradução de J. M. Justo. Lisboa: Antígona, 1995.

HOLANDA, S. B. Uma doença infantil da historiografia. In: Escritos coligidos, vol. 2. Org. Marcos Costa. São Paulo: Unesp/Fundação Perseu Abramo, 2011.

HUME, D. A treatise of buman nature. Ed. Selby-Bigge/Nidditch. Oxford: Clarendon Press, 1978.

HUME, D. The bistory of England, from the invasion of Julius Caesar to the 1688 revolution. Ed. William B. Todd, 6 vols. Indianapolis: Liberty Fund, 1983.

HUME, D. Of the populousness of ancient nations. In: Essays. moral. political. and literary. Ed. E. F. Miller. Indianapolis: Liberty Fund, 1985.

HUME, D. Da liberdade civil. In: A arte de escrever ensaio. Org. Pedro Paulo Pimenta. Tradução de Pedro Paulo Pimenta e Márcio Suzuki. São Paulo: Iluminuras, 2011.

HUME, D. Pbilosophical essays concerning buman understanding. 2 $2^{\mathrm{a}}$ edição, 1751. Ed. fac-símile. Hildesheim/New York: Olms Verlag, 1978.

KANT, I. Ideia de uma bistória universal de um ponto de vista cosmopolita. Organização e tradução de Ricardo Ribeiro Terra. $2^{a}$ edição. São Paulo: Martins Fontes, 2004. 
KANT, I. Começo conjectural da bistória bumana. Tradução de Edmilson Menezes. São Paulo: UNESP, 2009.

KANT, I. Antropologia Friedländer. In: Lectures on anthropology. Org. A. Wood e R. Louden. Cambridge: University Press, 2012. (Tradução desse curso: G. F. Munzel).

LÉVI-STRAUSS, C. L'éthnologie devant la condition humaine. In: Le regard eloignée. Paris: Plon, 1983.

MOMIGLIANO, A. Tacitus and the tacitist tradition. In: The classical foundations of modern bistoriograpby. Berkeley: University of California Press, 1990.

ZAMMITTO, J. Kant. Herder and the birth of antbropology. Chicago: University of Chicago Press, 2002.

Recebido em 11.11.2014 Aceito em 13.12.2014 